PREHOSPITAL CARE

\title{
Extrication of the seriously injured road crash victim
}

V Calland

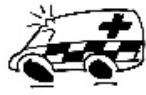

Emerg Med J 2005;22:817-821. doi: 10.1136/emj.2004.022616

See end of article for authors' affiliations

.....................

Correspondence to:

Dr V Calland, Med-ALERT,

48-49 Broadgate, Preston,

Lancashire, PR1 8DU, UK;

vic@victorcalland.co.uk

Accepted for publication 20 April 2005
In any accident scene, rapid removal of the casualty to hospital improves their chances of survival. The term the "Golden Hour" was first introduced in 1961, but because of misinterpretation as to what period this actually referrred to, a second concept, the Platinum Ten Minutes" was proposed as the time taken to move a casualty to the ambulance. To achieve this rapid removal, the ambulance and medical personnel must work in harmony with the police and fire service to secure the scene and remove the casualty safely without causing injury either to the casualty or other personnel on the scene. Care should also be taken to preserve evidence at the scene for future investigation. This paper describes the role of the emergency services, in particular that of the fire officer in charge, when attending the scene of a road traffic accident. The methods and equipment used to extricate a casualty from a motor vehicle are explained.
W hen the term the "Golden Hour" was first introduced in 1961 by R. Adams Cowley, rescue services tended to believe that it referred to the period from arriving on the scene to putting the casualty in the ambulance, rather than "crash to knife" time. The concept of the "Platinum Ten Minutes" was then proposed as an ideal for the on scene time, as it was realised that time had to be allowed for transit and emergency department assessment.

The "Platinum Ten Minutes" has placed considerable pressures upon the emergency services to reduce the time taken to extricate casualties from wrecked vehicles. Increasing awareness of the way in which poor handling affects the casualty, increasing concerns about safe working practice, increasing sophistication in vehicle design, and improvements in rescue tools have all been addressed by experts such as Mick McCarthy, ${ }^{1}$ Len Watson ${ }^{2-4}$ and the late Rob Walmsley ${ }^{5}$ to name but three. The work on extrication, however, has primarily been firefighter led. This article looks at the methods of extrication available in serious entrapment and the influence the immediate care practitioner can have.

In the UK, the overall responsibility for any accident scene lies with the police. At all incidents, however, the police will rely upon the advice of the fire service with regard to safety and rescue technique. ${ }^{6}$ In effect, therefore, the police will protect an outer cordon, and within the inner cordon only fire service and ambulance personnel will operate. Ambulance personnel and immediate care practitioners do not have authority to over-rule the fire officer present at the scene, merely being able to advise them of the consequences of any actions on a casualty. ${ }^{6}$

It is essential at every accident site that operations are managed to ensure that any evidence available at the site that may assist the investigatory bodies later is left as undisturbed as possible. Evidence such as tyre marks in the dew on the road, dirt from the wheel arches at the point of impact, or fragments of filament welded to headlamp glass can all be of value to the accident investigator. ${ }^{7}$ This evidence may not only be used in a prosecution, but also in a civil case for compensation for the victim.

Until recently, the emergency services worked either "in series" or "in parallel". "In series" operations occur when a sense of urgency has not developed. Everyone is courteous and stands aside if someone else needs access. This means the time lengthens dramatically. On other occasions, however, anxiety levels are high, and everyone tries to do their task simultaneously. This parallel working results in confused and often contradictory actions, and can cause accidents. The team approach ${ }^{8}$ proposes a working practice in harmony. Like an orchestra, all the rescuers work together, though there may be solo performances. There can be only one team leader, and that must be the fire officer in charge. $\mathrm{He}$ or she has the personnel, the rescue equipment, and also the responsibility as safety officer. For the team approach to work, all members of the team must not only know the game, but must know each other and train together. This article describes a little of the game; the rest will only be developed by getting to know the local emergency services.

In all crashes, there are the same stages of the rescue: $(a)$ establishment of scene safety and contact with the casualty to ensure airway control and protection of the cervical spine; (b) stabilisation of the vehicle and glass management; (c) gaining of entry to the vehicle and continuing stabilisation of the casualty; and (d) space creation to provide casualty extrication.

\section{EVACUATION TO HOSPITAL}

On arrival at an accident scene, the crew of a fire appliance will aim to protect the scene with an accident sign (if not already deployed by the police), lay out a hose reel and one or two dry powder extinguishers, stabilise the vehicles, start to remove the glass from the vehicle, and gain early access to the casualty to provide airway control and cervical spine immobilisation. They would aim to complete this within 2 minutes. They will start to lay out an equipment dump on a salvage sheet, and a similar sheet may be offered for medical and ambulance equipment. ${ }^{6}$

During this time, the fire officer in charge will be assessing the scene so that when the cutting equipment is ready he will be able to direct the crew to complete the necessary extrication procedure. The crew should be ready to make their first cut within 5 minutes of arrival.

The fire officer in charge has many factors to consider. His decision will be influenced by medical advice. His first decision is whether the rescue is a "snatch rescue", "rapid accessing", or a "controlled release". ${ }^{9}$ This decision is based both upon the condition of the casualty and the ability to provide both a safe working environment and safe working practice. The fire service will take no risk where life is not involved, but will take a risk if there is no other option to save life. 


\section{BOX 1 THE FOUR IMPACTS IN A ROAD CRASH}

(1) The car hits the object.

(2) The person hits the inside of the car.

(3) The person's organs hit the inside of the chest or abdominal wall.

(4) The rear passengers, pets, or objects hit the person in the front.

A "snatch rescue" may be little more than a controlled pull from the wreckage, or it may be the use of hydraulic spreaders to give space to breathe to a crushed victim, or it may even be use of a hydraulic cutting tool to amputate a foot to release the casualty when fire cannot be controlled. The "snatch rescue" is only rarely required.

Rapid accessing occurs when the casualty needs to be extricated within the Platinum Ten Minutes if the life is to be saved. This applies to the time critical casualty where further access is required to gain airway control, correct life threatening ventilation problems, control external haemorrhage, or where there is life threatening bleeding in to the skull, chest, abdomen, or pelvis that requires urgent surgical intervention. This is an area where medical guidance is crucial. Third impact injuries (box 1) account for the major cause of death to occupants of vehicles designed after 1996. ${ }^{10}$ These injuries are not visible, and physiological compensation can mask their presence in the early stages. The mechanism of injury is a key factor in alerting the rescuers to the potential need for rapid accessing and extrication.

The controlled release applies to the stabilised casualty where technique and comfort are principal considerations.

Looking in to the heart of the scene from the outside, the fire officer will look for issues of scene safety. He will seek to assess the numbers of casualties and their priorities for treatment. He will look for absolute constraints on the rescue-that is, one that cannot be overcome within the time available for a live rescue. A stone wall, a derailed locomotive, and an incoming tide are all examples of absolute constraints; there is no option but to work around them. Relative constraints are those that affect the rescue, but may be overcome; moving parked vehicles to give better access to the scene is an example of a relative constraint.

The fire officer will also need to look out from the inside. Starting from the casualty, he will look for lack of airway control, asphyxiation, impalement, entanglement, entrapment, and possible tamponade of abdominal haemorrhage by a steering wheel. He will look at the seat; does it recline, does it slide, is it powered?

He needs to decide the extrication path (the direction in which the casualty is removed from the vehicle). This will need to be cleared before the casualty is disentrapped. Medical procedures such as ketamine anaesthesia may be needed for disentrapment, and the situation of the casualty who then becomes unstable following the procedure, and yet cannot be extricated from the vehicle, needs to be avoided at all costs.

There are seven options available as extrication paths from the vehicle (fig 1). There is little doubt that the first choice is the extrication to the rear, but a variety of factors may prevent this. Generally, the other extrication paths are numbered in order of decreasing ease and favour. This is another area where the guidance of the medical personnel will be important.

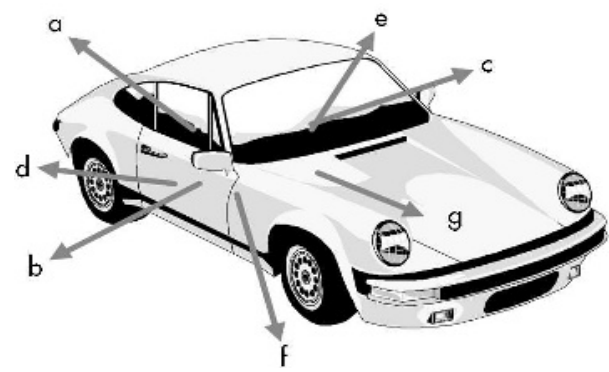

Figure 1 Potential vehicle extrication paths: (a) long board out to rear; rapid extrication, driver's door; (c) rapid extrication, opposite door; (d) long board and KED rear quarter oblique; (e) long board and KED rear quarter contralateral oblique; ( $f$ ) long board and KED feed first front quarter oblique; (g) appropriate for minibuses without a front mounted engine.

\section{METHODS OF EXTRICATION Long board out to the rear}

The method relies on the seat being reclined, and if the seat does not recline due to design or distortion from an ipsilateral side impact, this technique should not be used. The technique of lifting a critically injured person vertically up a long board because the seat does not recline should be avoided if at all possible. The idea of making such a casualty stand up in the emergency department would be universally condemned, and it should be similarly avoided at the accident scene. It is therefore important to recline the seat at an early stage, and this should always be undertaken as soon as airway control and cervical spine immobilisation has been carried out. There are several good reasons for this. Both the casualty and the working area are moved away from any undeployed air bags. Lowering the head to bring it more in line with the heart is a long accepted management for shock. The person applying in line stabilisation can do so from the side and will find the position more comfortable and will find it easier to explain to the casualty what is occurring. In addition, moving the patient into a recumbent position may mean that in the event of intra-abdominal injury, any haemostasis achieved by clot during the extrication procedure will be less likely to be disturbed during the slide onto the board. However, the possibility that the compression of the steering wheel may be providing tamponade of abdominal haemorrhage must not be forgotten. Injudicious removal of the wheel before disentrapment is complete and the extrication route prepared could lead to the death of the casualty while they are still trapped upright.

Remember the seat belts must be cut before attempting to lift the roof away from the vehicle. Seat belts should always be cut because this serves two purposes. Firstly, it is evidence for the police accident investigation team that the belt was on the person at the time of the crash (which may affect any compensation). ${ }^{7}$ Secondly, it stops any disreputable scrap dealer selling the belt, because, like crash helmets, once challenged they should be discarded. At the time of cutting the belt, note the position of the horizontal strap in relation to the anterior superior iliac crests. If it is below, then the force of deceleration was applied to the pelvis, which requires a force of $6 \mathrm{kN}$ to fracture it. If it is above the iliac crests, then not only could abdominal viscera have been ruptured at a mere $2.5 \mathrm{kN}$, but the victim may also have slid below the belt and sustained the classical dislocation of the hip, and fracture of the femur and patella described by Breton and Blondeau. ${ }^{11}$

Full roof removal is undertaken less frequently nowadays, for several reasons. Carrying the roof away requires four firefighters and involves lifting an unsupported weight with sharp edges over the casualty and any rescuers within the car. 
A gust of wind or downdraught of a helicopter air ambulance could wrench it from the control of the crew. It also requires the laminated and bonded screen to be separated from the roof and prevents its replacement if the weather conditions are bad. As a final complication, if the roof has been severely distorted and is in contact with the occupant's head, it will possibly move towards the casualty as the final cut is made, and cause further injury and pain.

The forward roof flap is therefore increasingly popular. It allows paramedics to work unhindered at the front of the vehicle while the $\mathrm{C}$ posts are cut (fig 2). Either the B posts are also cut high and the roof flapped forwards onto the crushed A posts, or two cuts in the roof just behind the B posts will allow a crease to be created in the roof and just the rear part of the roof folded forwards. When the front seats are reclined, the access for a long board is quite adequate (fig 3 ). This is a rapid procedure even in inexperienced hands, taking only about 4 minutes. While the roof is being attacked, it is often worthwhile to remove the bottom of the steering wheel with a "mini" or "pedal" cutter, because leg injuries, particularly posterior dislocation of the hip, can prevent a continuous slide along the long board. It is only as the casualty is slid along the board that traction can be applied to femoral fractures, and the use of ketamine at this stage is beneficial. Anaesthetic doses are best avoided until the roof can be flapped forward in case rapid sequence intubation is required. Zorab and Baskett suggested the use of triangular bandages to splint the legs together, ${ }^{12}$ but it is doubtful whether this would have significant effect on blood loss, and a rapid extrication and application of traction splintage is probably the superior option.

\section{Rear quarter oblique extrication}

A major cause of being unable to recline the front seat is its distortion by a side impact. The intrusion on the $\mathrm{B}$ post obstructs the movement or twists the back of the seat itself, often towards the intrusion. An intrusion in excess of $300 \mathrm{~mm}$ on the same side is a marker of potential serious third impact injury. This suspicion may be reinforced by discovery of a fractured humerus on the side of the impact. Furthermore, the side impact is associated with a higher incidence of cervical spine injury because the casualty often rotates their head to look at the oncoming vehicle and therefore prevents the ability of the cervical spine to extend.

The traditional method of providing side access to a casualty is the B post or American rip (fig 4). This involves firstly forcing the locking (Nader) bolt of the rear door, then cutting the top of the B post through the front and rear door window openings. A cut is made into the rear of the base of the B post at sill level, and spreaders used to force a tear through the rest of the post. The whole side of the car will then swing forwards on the front door hinges. The technique takes about 12 minutes if all goes well, but rust in the sill of older cars mean that the sill starts to crumble rather than the $\mathrm{B}$ post tearing if too deep an initial cut is made. The use of

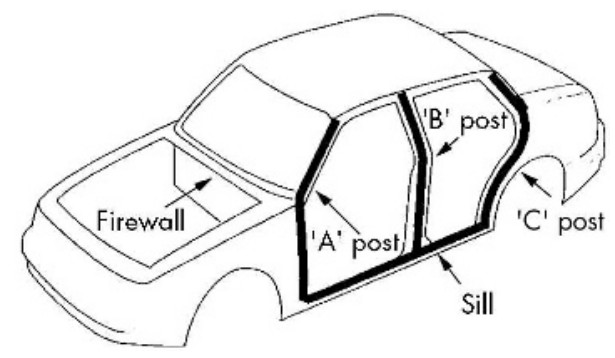

Figure 2 Components of a car body shell.

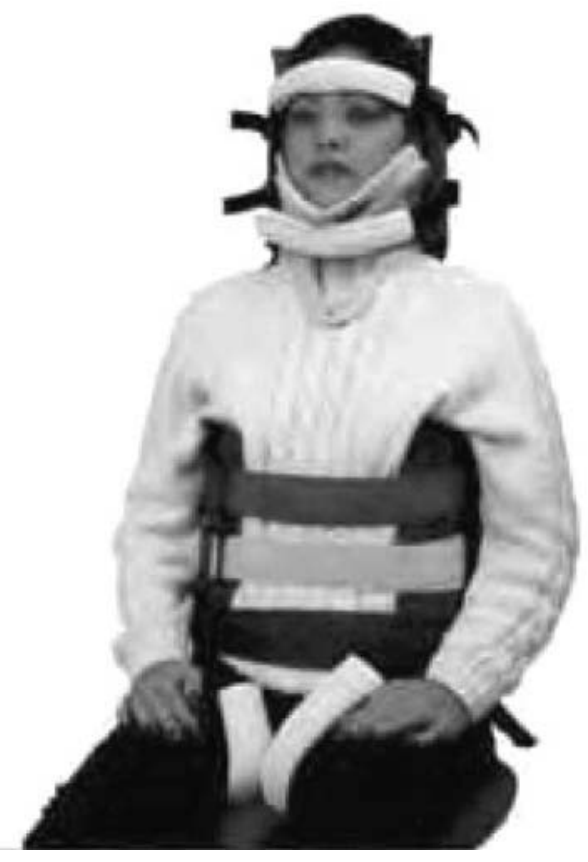

Figure 3 Extrication device in situ.

high strength light alloy (HSLA) in modern cars at the foot of the $\mathrm{B}$ post can also complicate matters, and even skilled operators may take 20 minutes or more to complete this task.

The casualty is usually removed on a long board along the rear quarter oblique extrication path. Because of the rotation required to achieve this, there is a rationale to using a Kendrick extrication device (KED) or equivalent, in keeping with the philosophy of the Joint Position Statement on Spinal Immobilisation and Extrication $^{8}$ if the cervical spine cannot be cleared. The problem is the difficulty in applying the KED with the roof still in position. Inserting it downwards between the casualty and the seat needs about $2.5 \mathrm{~cm}$ of clearance to avoid the problem of pushing it between shirt and trousers. Inserting it sideways behind the casualty means even more casualty movement and the benefit of the device rapidly begins to be offset. One advantage of the KED is that it provides strong lifting points and so may be of value when a heavy casualty is wearing flimsy clothing that will tear when used for lifting. Applying a KED can add 5 minutes or more to the extrication time, and so the value of using one must be judged in each case. Many rescue personnel are taught that all potential pre-hospital spinal injuries are considered unstable until proven otherwise, and will undertake a slow controlled release without realising that the third impact injuries make a rapid procedure essential. Immediate care practitioners may need to be firm in insisting that the theoretical risks of an unstable spine are outweighed by the rapidly decompensating cardiovascular status of the casualty.

If the vehicle is wrapped around a tree or lamp post, it may not be possible to access the casualty's side of the vehicle at all. If the back of the seat is rotated towards the midline of the car, then lowering the adjacent seat will facilitate extrication via a contralateral rear quarter oblique path. Such medial rotation of the seat back will occur if the impact is at or behind the B post, but momentum of the vehicle often then spins the car away from the obstruction, leaving side access available. If the impact is forward of the B post, there can be considerable footwell and A post intrusion, and the car often is embedded in to the object it has hit. The seat back is usually rotated away from the midline of the car, and the casualty has been rotated out of the diagonal strap of the 


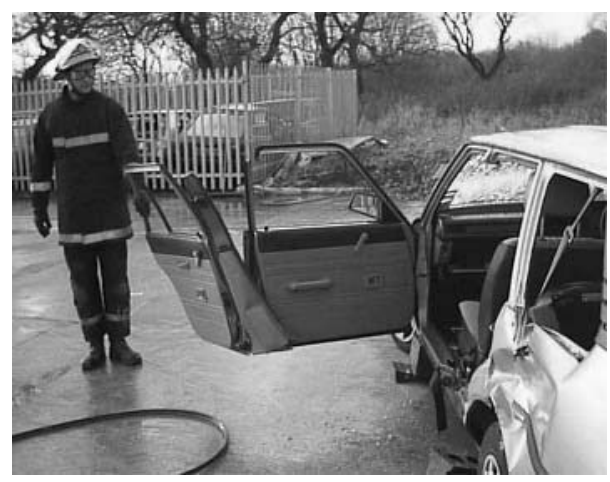

Figure 4 The American or "B" post rip.

seatbelt. In extreme cases, the casualty is sandwiched between door and seat, and the temptation is to cut away the back of the seat to enable the casualty to be pulled out. There are two reasons not to do so. Firstly, this will not free the legs from the footwell intrusion, and secondly, cutting a modern seat back is a complex issue, as they have been strengthened to withstand the fourth impact and can have airbags within them. Cutting one side may be successful, but cutting the second hinge will cause the seat back to rotate. Every situation is unique, but consideration must be given to winching the vehicle back to allow access to the deformed surfaces. As this will inevitably mean some shaking of the casualty, the fire officer will look to the medical personnel for guidance.

Winching or using hydraulic rams to reverse the forces of deformation on the vehicles can be a rapid method of extrication and is taught extensively in Norway following the work of Lars Wik et al. ${ }^{14}$ This technique is also popular in the USA and Canada as it avoids the sudden explosive splintering of plastic body panels that can occur with traditional cutting techniques. The system relies on being able to set up the rams and winches in such a manner as to precisely reverse the forces and constraints on access, and thus can prevent this useful method being implemented.

\section{Footwell entrapment}

If the occupant has become trapped by the lower parts of the body, the method termed a "dash roll" may be used to free the occupant. This can only be undertaken after the separation of the upper part of the A post from its connection via the roof to the $\mathrm{B}$ and $\mathrm{C}$ posts by a roof removal or flap.

The A posts will need to be cut low down. It has been custom and practice to make these cuts in the sills, but if this is done, there is a possibility of the floor pan rising up and trapping the casualty's feet. Furthermore, it is now common for fuel lines, hydraulics, and electrical wiring looms to be located in the sill. It is therefore more practical to make the cuts into the A post directly beneath the hinges. ${ }^{15}$

Modern car design provides a further complication to this procedure in that newer cars often have substantial amounts of HSLA steel at the bottom of the A post to help prevent intrusion of the front wheel into the footwell (fig 5). There may now also be a crosspiece of Boron steel built into the dash structure, which would prevent a dash roll being completed with only one A post being cut through. A ram or pair of rams seated at the base of the B post and acting on the upper part of the A post (alongside the upper door hinge) will roll the front of the car forwards.

By cutting through the A post both at sill and dash level, the metalwork of the internal wing that can conceal foot entrapment may be mobilised. The metal is either pushed out of the way with a power ram or pulled away using the

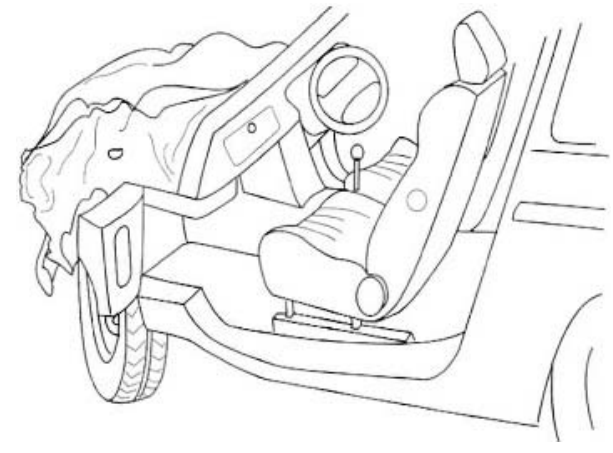

Figure 5 Footwell clearance.

leverage of spreaders. This process takes about 6 minutes. Pieces of soundproofing material or plastic fascia may need removal by hand before the condition of the ankles and feet can be determined.

\section{Access to rear seat passengers}

The rear seats usually fold forward rather than back, and therefore extrication to the rear is prevented. Furthermore, any casualty in the rear will need to be removed before a long board to the rear can be used on front seat occupants. The door usually needs to be removed and the casualty extricated to the side. In the case of rear shunts, this can be difficult, as the distance between the rear and front seats is foreshortened. In these circumstances, the front passengers will need to be removed by a side or oblique approach, and the front seat will need to be mobilised to create access to the rear passengers.

In the case of a two door car the bodywork between the B and $\mathrm{C}$ posts can be removed (fig 6) by cutting the B post high and low, and then cutting either vertically down in front of the $\mathrm{C}$ post (at the rear of the rear side window) or continuing the horizontal cut from the B post at sill level. Both cuts may be required. Leverage of the isolated section of side wing will allow more room for manoeuvring the casualty, or reaching those in the rear seats. In some vehicles, the presence of the petrol tank filler hose will prevent this technique being used.

\section{The overturned car}

The "long board lower" is a technique for situations in which the casualty is suspended upside down from the seat by their seatbelt. It requires the roof not to have been crushed. The doors are forced and a ratchet strap, line, or length of hose is used to take the weight of the casualty by passing across the width of the car and tensioning by two firefighters. The rear is also opened. A long board is passed along the roof of the car until it is below the casualty. The back of the seat is reclined, the seat belt cut, and the casualty lowered to lie

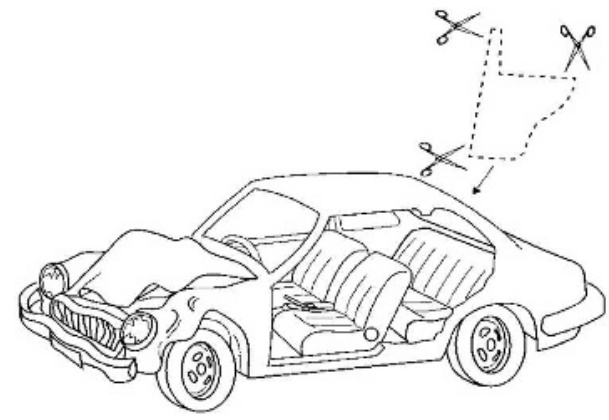

Figure 6 Third door creation. 


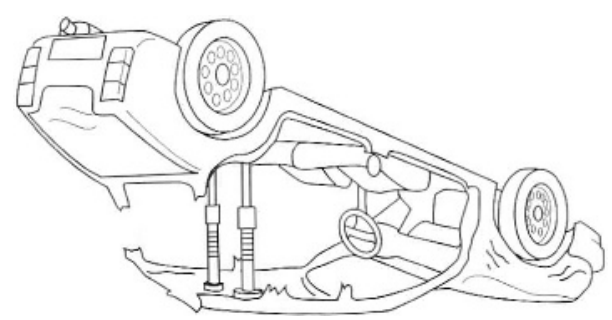

Figure 7 The rear oyster.

prone on the board, which is then removed. This procedure can be completed in 10 minutes or less.

In high speed rollovers, the front windscreen pillars are unable to sustain the force applied, and are bent towards the rear of the car. Because this jams the doors, the only access is usually from the rear. To provide a better extrication path the inverted B post rip may be employed. In many ways, this is an easier technique to perform than the classical version. It gives good and rapid access to the vehicle, and may then be further developed by conversion into an oyster. There are two variations, the rear oyster and the side oyster.

The rear oyster

The casualty in a rollover that has flattened the A posts (fig 7) may be flung around the car if they are not wearing a seatbelt, in which case the injuries are severe and possibly fatal, or if belted, will still be in their seat. They are usually upside down and have their head acutely flexed against the roof. Premature cutting of the seat belt results in the entire weight of the body being carried on the acutely flexed neck, and should be avoided at all costs. This is a time critical entrapment, for while the crew will want to work slowly to avoid risk to the cervical spine or themselves, the persistent acute flexion of the neck for periods in excess of an hour has been found to cause a permanent cord lesion because of ischaemia resulting from the traction and compression of cord vessels even in the absence of a fracture.

It is essential that two hydraulic rams are placed on a stable section of the roof near the rear, and extension pieces or blocks used to ensure the full extension of the ram will serve to lift the car bodywork. At least 200-300 millimetres will be required to allow neutral alignment of the cervical spine to be achieved. The rams are tensioned until there is distortion of the metalwork of the car. The C and B posts are cut on both sides, and hydraulic rams are used on both sides to open the car like an oyster. With two rams at their maximum extension, there is a little loss of lateral stability, but two firefighters can provide all the lateral support required. The technique is completed with a "long board lower" extrication. This technique is quite rapid if the vehicle is not too badly damaged as in the training scenario. In real life, however, it can take much longer.

\section{The side oyster}

In this technique the $\mathrm{A}, \mathrm{B}$, and $\mathrm{C}$ posts on one side of the vehicle are cut and a ram is used to open the vehicle along the side. This method may appear to be unstable but the major part of a car's weight is in the engine and this is always to be found resting on the ground, providing rigid three point contact. By using either a telescopic ram or two rams to alternate the lift, a full metre of clearance can be obtained by the experienced operator.

\section{CONCLUSION}

The fire service has developed a variety of techniques to enable them to extricate a casualty from a wrecked motor car. These methods have indications, contraindications, special precautions, and side effects in the same manner as any other therapeutic intervention. However, because of their intimate proximity, neither vehicle nor casualty can be considered in isolation, but all too often there has been a lack of consultation at the development stage between extrication experts and pre-hospital care practitioners.

Doctors and paramedics involved in road traffic crashes need to be familiar with extrication technique just as firefighters need a greater understanding of the physiological effects their procedures can have on crash victims. Joint training is required to overcome the current deficiencies.

Competing interests: none declared

\section{REFERENCES}

1 International Emergency Technical Response Institute. www.fire.org.uk.

2 Wilmink AB, Samra GS, Watson LM, et al. Vehicle entrapment rescue and pre-hospital trauma care. Injury 1996;27:21-5.

3 Watson LM. RTA, persons trapped. Vehicle accident rescue. Halstead: Greenwave, 1990.

4 Watson LM. MVA rescue technician - mechanisms of injury. Halstead: ResQMed, 1999.

5 International Centre for Emergency Techniques. www.icet.nl.

6 Fire Service College. Operations Manual, Chapters RTAI 01-1. Moreton-inMarsh, Oxfordshire..

7 Drury J. Guidance for emergency services at road traffic crashes, Lancashire Constabulary, 1998

8 Ersson A, Lundberg M, Wramby CO, et al. Eur J Emerg Med 1999;6:341-7.

9 Watson L. How will supplementary restraints systems affect occupational safety?. Halstead: ResQMed, 1997.

10 National Center for Statistics and Analysis of the National Highway Traffic Safety Administration. Fatality analysis reporting system data, wwwnrd.nhtsa.dot.gov.

11 Breton $\mathrm{M}$, Blondeau $\mathrm{A}$. Une variété de luxation de la hanche avec fracture du sourcil cotyloïdien, observée après certain accidents d'automobile. J Radiol Electrol 1927;11:430.

12 Zorab J, Baskett P. Immediate care. London: Saunders Co, Ltd, 1977.

13 Faculty of Pre-hospital Care of the Royal College of Surgeons of Edinburgh and the Joint Royal Colleges Ambulance Service Liaison Committee. 1998 joint position statement on spinal immobilisation and extrication. J Pre-hosp Imm Care 1998;2:169-72.

14 Wik L, Hansen TB, Kjensli K, et al. Rapid extrication from a car wreck. Injury 2004;35:739-45.

15 Calland V. Safety at scene - a manual for paramedics \& immediate care doctors. Edinburgh: Mosby, 2000. 